\title{
INDÚSTRIA CULTURAL E DISTRAÇÃO CONCENTRADA: AS PLATAFORMAS DIGITAIS E O ENSINO PERSONALIZADO
}

\author{
CULTURAL INDUSTRY AND CONCENTRATED DISTRACTION: \\ DIGITAL PLATFORMS AND PERSONALIZED TEACHING \\ INDUSTRIA CULTURAL Y LA DISTRACCIÓN CONCENTRADA: \\ PLATAFORMAS DIGITALES Y EDUCACIÓN CUSTOM
}

\author{
Camila Sandim de Castro ${ }^{\mathrm{I}}$ \\ Antônio Álvaro SoARes ZuIN ${ }^{I I}$
}

Resumo A cultura digital se faz cada vez mais presente nas salas de aula por meio do uso de recursos tecnológicos, como as plataformas digitais de ensino e aprendizagem. De fato, professores têm usado tais recursos, principalmente com a intenção de atenuar o desinteresse dos alunos pela transmissão dos conteúdos das disciplinas escolares. Contudo, os mesmos aparelhos empregados na educação como tentativa de sanar tal desinteresse estão contribuindo para acentuar a falta de concentração de professores e alunos em suas atividades escolares. Um dos motivos é a utilização acrítica dessas plataformas, entre as quais se destaca a Geekie. Por intermédio do chamado ensino personalizado, essa plataforma tem atingido um número crescente de professores e alunos ao oferecer diversas opções de ensino e aprendizagem virtual, especialmente para o Ensino Médio e vestibulandos. Ancorado no aporte teórico da chamada Teoria Crítica da Sociedade, sobretudo em Theodor W. Adorno, Max Horkheimer e Christoph Türcke, os autores deste artigo têm como objetivo discutir os efeitos da utilização acrítica das plataformas digitais de ensino e aprendizagem para o processo formativo de professores e alunos, principalmente por meio da promoção do ensino personalizado.

Palavras-chave: Teoria Crítica da Sociedade; Cultura Digital; Ensino Personalizado.

I Doutoranda em Educação pelo Programa de Pós-Graduação em Educação da Universidade Federal de São Carlos (UFSCar). Professora da Rede Municipal de Ensino de Barroso/MG.

II Doutor em Educação pela Universidade Estadual de Campinas (UNICAMP). Professor titular do Departamento de Educação e do Programa de Pós-Graduação em Educação, Universidade Federal de São Carlos. Bolsista Produtividade em Pesquisa CNPq. 
Abstract Digital culture is becoming more and more present in classrooms through the use of technological resources, such as digital teaching and learning platforms. In fact, teachers have used these resources mainly with the intention of attenuating student's lack of interest in the transmission of the contents of the school subjects. However, the same devices used in education as an attempt to remedy such disinterest are contributing to accentuate the lack of concentration of teachers and students in their school activities. One of the reasons is the uncritical use of these platforms, among which Geekie stands out. Through so-called personalized teaching, this platform has reached an increasing number of teachers and students by offering several options for teaching and virtual learning, especially for high school and college students. Annotated in the theoretical contribution of the so-called "Critical Theory of Society", especially in Theodor W. Adorno, Max Horkheimer and Christoph Türcke, the authors of this article have as objective to discuss the effects of the uncritical use of the digital platforms of teaching and learning for the formative process of teachers and students, mainly through the promotion of personalized teaching.

Key-words: Critical Theory of Society; Digital Culture; Customized Teaching.

Resumem La cultura digital se hace cada vez más presente en las aulas mediante el uso de recursos tecnológicos, tales como las plataformas digitales de enseñanza y aprendizaje. De hecho, los profesores han utilizado tales recursos, principalmente con la intención de atenuar el desinterés de los alumnos por la transmisión de los contenidos de las disciplinas escolares. Sin embargo, los mismos aparatos utilizados en la educación como intento de sanar tal desinterés están contribuyendo a acentuar la falta de concentración de profesores y alumnos en sus actividades escolares. Uno de los motivos es el uso acrítico de esas plataformas, entre las que destaca a Geekie. A través de la llamada enseñanza personalizada, esta plataforma ha alcanzado un número creciente de profesores y alumnos al ofrecer diversas opciones de enseñanza y aprendizaje virtual, especialmente para la Enseñanza Media y vestibulandos. En el acto teórico de la llamada "Teoría Crítica de la Sociedad", sobre todo en Theodor W. Adorno, Max Horkheimer y Christoph Türcke, los autores de este artículo tienen como objetivo discutir los efectos de la utilización acrítica de las plataformas digitales de enseñanza y aprendizaje para el proceso formativo de profesores y alumnos, principalmente a través de la promoción de la enseñanza personalizada.

Palabras clave: Teoría Crítica de la Sociedad; Cultura Digital; Enseñanza personaLIZADA.

\section{INTRODUÇÃo}

Os aparatos tecnológicos têm sido cada vez mais utilizados por professores e alunos nos espaços formais de ensino como as salas de aulas, com o intuito de promover um ensino mais atraente e uma aprendizagem significativa. Pesquisadores das Ciências da Informação e Comunicação como Pierre Lévy ressaltam os aspectos emancipatórios das tecnologias educacionais, como o acesso e o compartilhamento de informações, a cons- 
trução de novas formas de aprendizagem, a interatividade e a democratização do conhecimento socialmente legitimado. Para Lévy (1999), a utilização dos aparelhos tecnológicos no processo educativo impulsiona o corpo docente a repensar a prática pedagógica criando novas metodologias, logo, ressignificando o próprio conceito de ensino. Nesses termos, as chamadas tecnologias intelectuais podem favorecer:

[...] novas formas de acesso à informação: navegação por hiperdocumentos, caça à informação através de mecanismos de pesquisas, [...] e novos estilos de raciocínio e de conhecimento, tais como a simulação, verdadeira industrialização da experiência do pensamento (LÉVY, 1999, p. 157).

Ainda, segundo o autor, a cibercultura, ao possibilitar o acesso à informação, promove uma mudança na relação com o saber ao construir novas formas de comunicação e de aprendizagens, fazendo que a construção do conhecimento na cultura digital passe a ser colaborativa. De fato, a presença das tecnologias no ambiente escolar tem produzido mudanças na maneira como o conhecimento é produzido, internalizado e ressignificado.

Diante das discussões realizadas por Lévy (1999) a respeito da cibercultura, é possível afirmar que os aparatos tecnológicos podem contribuir para o processo formativo, desde que sejam compreendidos e usados de maneira crítica, tendo como objetivo fomentar a emancipação de professores e alunos. Contudo, em muitas práticas pedagógicas o uso das tecnologias educacionais tem sido acompanhado da ilusão de que um ensino condizente com as necessidades e exigências contemporâneas deve ser aquele que utiliza esses aparatos para dinamizar e facilitar o ensino e a aprendizagem. Assim, graças ao uso de computadores, celulares, tablets, internet tem-se evidenciado uma aceleração do processo formativo, reduzindo-o a uma espécie de capacidade de armazenamento de informações. Em tempos de ensino mediado pelas tecnologias educacionais, a crença nesses aparatos como possibilidade de oferecer uma educação de qualidade se reforça mediante um número cada vez maior de instituições de ensino que têm empregado tais tecnologias como forma de proporcionar espaços supostamente formativos. Entre essas tecnologias se destacam as plataformas digitais de ensino e aprendizagem que, pautadas no chamado ensino personalizado, vêm conquistando cada vez mais usuários e contribuindo para intensificar a chamada distração concentrada. Sendo assim, diante da presença das plataformas digitais no ambiente escolar, torna-se necessário refletir criticamente sobre o modo como estão sendo utilizadas e entendidas à medida que têm contribuído para alterar o processo de ensino e aprendizagem e, por conseguinte, a relação pedagógica entre professores e alunos.

Diante desse contexto, os autores deste artigo têm como objetivo discutir os efeitos da utilização acrítica das chamadas plataformas digitais de ensino e aprendizagem para o processo formativo de professores e alunos, principalmente por meio da promoção do chamado ensino personalizado. Para tanto, este trabalho tem como aporte teórico as contribuições de pensadores da Teoria Crítica da Sociedade, especialmente Theodor W. Adorno, Max Horkheimer e Christoph Türcke. Tais pensadores possuem uma visão dialética dos aparatos tecnológicos, e ao compreendê-los como produtos culturais, incitam a reflexão a 
respeito do desenvolvimento das forças produtivas capitalistas e suas consequências para a formação cultural. Adorno e Horkheimer trazem contribuições pertinentes ao discutirem a contradição historicamente construída sobre o papel da técnica atrelada ao capital que foi responsável pelo processo de mercadorização da cultura conhecido como indústria cultural. Já Türcke (2010a), amparado na ideia de "contrafogo" desenvolvida por Pierre Bourdieu (1998), propôs que o chamado choque imagético disseminado pelos produtos da indústria cultural fosse transformado em choque reflexivo ou em "imagens-pensamento" em termos benjaminianos. Tal transformação requer um exercício de concentração e reflexão diante das imagens que são cotidianamente consumidas por professores e alunos, de modo que o pensamento estereotipado seja substituído pelo pensamento crítico. Exercício que tem sido corriqueiramente solapado pela "torrente de estímulos audiovisuais" difundida pelas mercadorias da indústria cultural como as plataformas digitais de ensino e aprendizagem. Sendo assim, a primeira seção apresenta uma discussão a respeito do chamado ensino personalizado que tem atraído professores e alunos por proporcionar uma abordagem dinâmica dos conteúdos disciplinares por meio da utilização das plataformas digitais. A segunda seção discute os efeitos do uso dessas plataformas para o processo educativo, entre eles, a distração concentrada como produto do consumo acrítico dos choques audiovisuais proporcionados pelos aparatos tecnológicos que têm contribuído para o distanciamento de professores e alunos da formação cultural.

\section{O PROCESSO EDUCATIVO, AS PLATAFORMAS Digitais E O ENSINO PERSONALIZADO}

Atualmente, as chamadas tecnologias educacionais estão sendo disseminadas por todos os níveis do ensino escolar, desde a educação básica até a educação superior, prometendo aos professores e alunos alcançarem resultados bem-sucedidos no processo de ensino e aprendizagem. Entre essas tecnologias estão as denominadas plataformas digitais de ensino e aprendizagem, que têm se tornado cada vez mais conhecidas, principalmente entre professores e alunos do Ensino Médio e vestibulandos. Tais plataformas fazem uso do chamado ensino personalizado. Ancorado nos aparelhos tecnológicos, esse ensino tem como característica o fato de os estudantes terem liberdade para acessar quaisquer conteúdos disciplinares a qualquer tempo. Seu principal objetivo é inserir o estudante no cerne do processo de aprendizagem e disponibilizar ferramentas tecnológicas que possam auxiliá-lo na construção de seu conhecimento (ROTHMAN, 2013). Esse novo modelo de ensino é necessário, segundo Rothman (2013), à medida que a geração interativa, constituída por aqueles que nasceram em meio ao mundo digital, domina cada vez mais as diferentes tecnologias, que as empregam como ferramentas de pesquisa e estudo em suas atividades escolares. Entre algumas das plataformas digitais ${ }^{1}$ existentes que

Essas plataformas disponibilizam conteúdos disciplinares no formato de vídeos e jogos interativos com o objetivo de facilitar e dinamizar o processo educativo. Além disso, conseguem coletar dados e informações referentes ao desempenho dos alunos disponibilizando-os aos professores por meio dos resultados obtidos 
utilizam o ensino personalizado podem ser citadas: Khan Academy, Mangahigh, Geekie, Descomplica e Hora do ENEM.

Dessa forma, as tecnologias educacionais estão sendo entendidas como capazes de dinamizar o processo de ensino e aprendizagem, ao oferecerem opções diferenciadas em comparação à tradicional aula expositiva como os jogos interativos para abordar os conteúdos disciplinares ao propor exercícios supostamente mais atraentes para os alunos. No caso da plataforma Geekie, ${ }^{2}$ são oferecidos testes on-line para identificar o perfil do aluno e planejar um roteiro de estudo condizente com o que foi detectado no teste, permitindo, assim, que a escola acompanhe o desempenho dos estudantes. Além de a plataforma organizar e adaptar o conteúdo disciplinar ao modo como cada aluno aprende, há um espaço destinado apenas para vestibulandos, que contém simulados, planos de estudos, videoaulas, questões a respeito das videoaulas e o Simulador Sisu (Sistema de Seleção Unificada), que indica as áreas do conhecimento e as respectivas universidades que poderiam ser cursadas de acordo com a pontuação obtida nos testes on-line. No link "Outras aulas" estão disponíveis os conteúdos disciplinares avaliados no Exame Nacional do Ensino Médio (Enem) como Redação, Filosofia, Matemática, Português etc. Acessando o tópico "Filosofia", são encontradas oito aulas, quais sejam, "Filosofia iluminista", "Evolução científica", "Conceitos de cidadania e democracia", "Teorias sobre ética e moral", "Teoria do conhecimento", "Arte e estética", "Filosofia medieval" e "Filosofia grega". Cada aula tem um vídeo explicativo com duração média de quinze minutos e duas questões sobre a temática abordada. Além do espaço para o aluno, existe no site da Geekie um espaço destinado aos professores em que é possível, ao criar gratuitamente uma conta na plataforma, selecionar a disciplina ministrada, por exemplo, "Biologia" e criar uma tarefa para os alunos clicando acerca da temática a ser estudada como "Fisiologia vegetal". Existem diversas questões de múltiplas escolhas prontas, bastando ao professor apenas imprimir a folha com as questões selecionadas para que os alunos respondam. Na verdade, nem é preciso imprimir o material, pois é possível

pelos estudantes ao realizarem os exercícios interativos disponíveis nas plataformas. Nessas plataformas ainda é possível acessar questões resolvidas de provas anteriores como no caso da "Descomplica" e "Hora do Enem", videoaulas, monitorias, testes on-line que identificam o perfil de aprendizagem dos alunos, quizzes matemáticos, entre outros. Para saber mais, acesse: Plataforma Khan Academy. Disponível em: https:// www.khanacademy.org/. Acesso em: 3 março 2017. Plataforma Mangahigh. Disponível em: https://www. mangahigh.com/pt-br/ Acesso em: 3 março 2017. Plataforma Geekie. Disponível em: http://www.geekie. com.br/. Acesso em: 3 março 2017. Plataforma Descomplica. Disponível em: https://descomplica.com.br/. Acesso em: 3 março 2017. Plataforma Hora do ENEM: Disponível em: http://tvescola.mec.gov.br/tve/serie/ hora-do-enem Acesso em: 3 março 2017.

2 A Geekie foi desenvolvida pelo arquiteto Claudio Sassaki e pelo administrador de empresas Eduardo Bontempo, ambos com pós-graduação na área da Educação. Para a análise crítica das plataformas digitais de ensino e aprendizagem, optou-se por selecioná-la, porque tal plataforma apresenta um número significativamente maior no que se refere às possibilidades interativas como testes on-line, videoaulas, questões, planos de estudos, tarefas de casa etc. disponíveis para alunos, professores e escolas quando comparada às demais plataformas citadas neste artigo. Além disso, conforme informações do site, a Geekie é a "única plataforma adaptativa credenciada pelo MEC". É importante destacar que tal plataforma disponibiliza serviços gratuitos, assim como oferece pacotes de estudos pagos. Segundo informações do site, para cada escola privada que compra os serviços disponíveis na plataforma, uma escola pública passa a ter acesso gratuito à Geekie. 
encaminhar pelo próprio site da plataforma as questões para os alunos, assim como indicar videoaulas para que eles assistam.

Assim, o ensino mediado por tecnologias que têm como pressuposto a utilização de vídeos, jogos e a interação virtual de professores e alunos se apoia na oferta da diversão e praticidade como forma mais eficaz de educar, disseminando uma crença nos aparatos tecnológicos como meios eficientes para promover uma educação formativa. Isso se reverbera nas palavras de Moran (2004), ao afirmar que "é importante que os alunos estejam mais motivados, tenham mais iniciativa, explorem novas possibilidades. E as tecnologias podem ser um excelente auxiliar na tarefa de desenvolver esse aluno mais empreendedor e inovador" (MORAN, 2004, p. 349). E conclui, "não podemos permanecer imobilizados, no entanto, porque educação de qualidade hoje se faz com soluções inovadoras pedagógicas, gerenciais e tecnológicas" (MORAN, 2004, p. 355). Essa nova proposta de ensino tem ainda como característica uma mudança na função do professor, que consiste em orientar as atividades a serem desempenhadas pelos alunos atuando como colaborador e não mais como autoridade pedagógica responsável pelo processo educacional. De fato, o professor não precisa mais executar as atribuições da docência como outrora, considerando os serviços oferecidos pelas plataformas digitais, pois as tarefas para os alunos resolverem em casa já estão prontas, bastando apenas selecioná-las entre as quatro mil questões oferecidas pela Geekie. Ou seja, o exercício docente de consultar livros, dicionários, filmes, pinturas e a própria internet, a fim de retomar o material ministrado em sala de aula, buscando elementos conceituais para refletir e elaborar uma questão para os alunos responderem, é feito pela própria plataforma. Ao ser relegado à função de colaborador, o professor passa a ser entendido como uma ferramenta do professor formativo e não mais como alguém que detém os saberes necessários para mediar a construção do conhecimento de seus alunos. Adorno (2010) esclarece que o professor enquanto uma das figuras de autoridade da sociedade pré-burguesa era responsável por fazer a mediação entre a tradição e os indivíduos. Ou seja, era graças à figura do professor que os alunos podiam reter o espírito, de modo a terem "um contato corporal com as ideias", ao se concentrarem nos conteúdos necessários para a sua formação.

Nesses termos, as plataformas digitais, ao transformarem o professor em um mero artefato do processo educativo, oferece aos alunos a falsa ideia de poder personalizar seus estudos conforme suas aptidões e interesses, pois a plataforma já está previamente organizada de tal forma que a possibilidade de intervenção é negada, uma vez que até os sujeitos do processo educativo, a saber, professores e alunos, são transformados em apêndices de tais plataformas. Franco (2004), ao analisar a tecnologia na era da globalização, assevera que "sustentada por várias tecnologias interativas, ela [a indústria cultural] não parece mais pressupor um consumidor passivo nem oferecer um produto acabado, com determinado conteúdo ou modo de representação" (FRANCO, 2004, p. 204). A indústria cultural, como esclarece o autor, passou a oferecer "a promessa de que o usuário de determinado equipamento irá conseguir interagir com ele de muitas maneiras, podendo alcançar resultados criativos e originais" (FRANCO, 2004, p. 204). Mas, na verdade, a tecnologia "mascara, 
na promessa de atividade, uma nova qualidade de submissão" (FRANCO, 2004, p. 205).

Enquanto a autoridade pedagógica é colocada em xeque pela disseminação das plataformas digitais - afinal, para que serve o professor, já que o acesso à informação se torna cada vez mais disponível para os alunos? - não se pode negar que os alunos tendem a assumir uma postura mais ativa frente ao próprio aprendizado com o uso das tecnologias educacionais. Tal postura é importante para o processo formativo dos alunos à medida que eles podem buscar nas videoaulas disponíveis, por exemplo, pela Geekie, a resolução de dúvidas que se fizeram persistentes durante as explicações em sala de aula pelo professor. Contudo, para o aprendizado dos conteúdos escolares é indispensável a figura do professor, que em tempos de ensino personalizado tem como função incitar a construção do espírito crítico em relação aos efeitos deletérios causados pelo consumo acrítico dos aparatos tecnológicos. Desse modo, corroborando o entendimento de Franco (2004) acerca das tecnologias educacionais interativas, ao mesmo tempo permitindo pensar a respeito da função docente para o uso das tecnologias, Pucci e Ramos-de-Oliveira (2007) asseveram que "a maior parte dos escritos sobre a ciência moderna e a tecnologia contemporânea tende a enfatizar [...] os inegáveis benefícios do progresso para a humanidade: a elevação geral do nível de vida com o desenvolvimento das forças produtivas materiais", mas, segundo os autores, "existe também o lado sombrio das novas tecnologias, que pesa de maneira assustadora sobre nós. E esse lado obscuro precisa também ser iluminado, para que apareça em toda a sua crueza" (PUCCI; RAMOS-DE-OLIVEIRA, 2007, p. 42).

Nesse contexto, o discurso de que as tecnologias educacionais promovem um ensino que condiz com os desafios e as necessidades do século XXI está dissimuladamente carregado das exigências capitalistas, a saber, a produção de mão de obra especializada para o mercado de trabalho. Sendo assim, a educação hodierna tem preparado as pessoas desde a infância para que sejam "afinadas com a técnica", para usar uma expressão de Adorno (1995), a fim de que possam executar as atividades do trabalho que aparecem cada vez mais imbricadas à utilização dos aparelhos tecnológicos. A realização dessas atividades é produto daquilo que Adorno (2010) chamou de semiformação (Halbbildung), ou seja, o fenômeno resultante do modo alienado de se relacionar com os produtos culturais, graças ao processo de reificação da consciência que teve como principal consequência o distanciamento do indivíduo da formação cultural. Adorno (1995) concebe a formação cultural como sendo a formação plena do indivíduo em termos culturais, assim a Bildung envolve a emancipação, a autonomia, a experiência e o pensamento crítico-dialético. Ademais, a formação cultural possui uma dimensão ética que diz respeito à coerência entre o pensamento e a ação, ou seja, a Bildung é responsável pela promoção da sensibilização, de forma que o indivíduo, ao compreender, por exemplo, a barbárie expressa no racismo, não será conivente com atitudes racistas. Desse modo, a formação cultural é o revés da heteronomia, do não esclarecimento e do pensamento estereotipado e autoritário. A formação cultural está voltada para a contradição e para a resistência, de tal maneira que o momento da adaptação dos indivíduos à cultura tem como finalidade transformá-los em sujeitos pensantes, críticos e questionadores, ao invés de produzir "pessoas bem ajustadas" (ADORNO, 1995, p. 143). 
A Halbbildung é produto da indústria cultural e "apesar de toda ilustração e de toda informação que se difunde (e até mesmo com sua ajuda), a semiformação passou a ser a forma dominante da consciência atual" (ADORNO, 2010, p. 9). Nesses termos, a semiformação se reverbera, por exemplo, no ingresso prematuro das crianças nas escolas, as quais devem realizar uma série de atividades supostamente pensadas para estimular seu desenvolvimento cognitivo estando pautadas no uso de tecnologias. Diante de uma infinidade de exigências escolares voltadas para atender ao mercado de trabalho, as crianças vêm sendo submetidas ao aprendizado de toda parafernalha tecnológica, não sendo possibilitado a elas o exercício de refletirem sobre o que estão fazendo. Assim, as informações consumidas pelas crianças, por intermédio do contato com os aparelhos tecnológicos, não são gravadas na memória, pois não há tempo para se apropriarem nem refletirem acerca do que estão consumindo. Tais informações aparecem e são tratadas como dadas, desvinculadas do processo histórico e social e, nessa medida, como adverte Adorno (2010), "a experiência [...] fica substituída por um estado informativo pontual, desconectado, intercambiável e efêmero, e que se sabe que ficará borrado no próximo instante por outras informações" (ADORNO, 2010 , p. 33). Na verdade, o aprendizado desse conjunto de tecnologias se fundamenta hegemonicamente no controle de operações que lhes permitam acessar informações por meio dos denominados softwares educacionais. Desse modo, quando os estudantes conseguem utilizar de forma satisfatória certa tecnologia, outra mais complexa já está sendo comercializada, havendo assim pouca preocupação em promover o pensamento crítico para lidar com esses aparatos. Nesse sentido, é possível perceber que o processo de construção do conhecimento e da autonomia encontra barreiras para se estabelecer em função do modo acrítico que as pessoas, desde a infância, começam a se relacionar com as tecnologias. Como lembra Adorno (1995), os indivíduos passam a se relacionar com as coisas como se fossem pessoas e com as pessoas como se fossem coisas. É a esse lidar com as coisas de forma não autônoma que, conforme o pensador, a técnica passa a ocupar um lugar decisivo na vida das pessoas, transformando-as em "pessoas tecnológicas, afinadas com a técnica" (ADORNO, 1995, p. 132).

Nesse sentido, o controle do tempo e a ênfase na eficiência ainda são as peças-chave da engrenagem capitalista, além da disseminação do espírito conformista e não reflexivo. O ensino personalizado, nesse contexto, pode ser entendido como uma nova espécie de exploração capitalista que acontece não apenas sob a forma da exploração física e econômica, como no período da Revolução Industrial no século XVIII, mas, sobretudo com a exploração do sensório humano. Isso se verifica, por exemplo, quando os estudantes, ao utilizarem as plataformas digitais, se deparam com infinitos estímulos audiovisuais, que em vez de os ajudarem na compreensão dos conteúdos disciplinares, acabam contribuindo para promover uma espécie de agitação sensório-motora, como será discutido na seção seguinte. No caso da plataforma Geekie há diversas imagens, jogos, vídeos etc. disponíveis para o acesso com o intuito de ensinar o conteúdo de cada disciplina escolar. No entanto, são oferecidas tantas opções de navegação pelos conteúdos que os alunos podem facilmente se distraírem enquanto os acessam. Se um estudante estiver assistindo a uma aula de "Geografia" pode, 
por exemplo, acessar as aulas de "Química" clicando em "Outras aulas", aba disponível na mesma janela em que o conteúdo de "Geografia" está sendo ministrado. Assim, inseridos em um ensino que dificilmente promove uma aprendizagem crítica e autônoma para o uso das tecnologias, lhe restam poucas alternativas a não ser se adaptarem a cada exigência requerida pelos aparatos tecnológicos. Herbert Marcuse, ao analisar as transformações sociais da racionalidade, afirma que a tecnologia moderna é responsável por transformar a "força crítica [da racionalidade] em uma força de ajuste e submissão" (MARCUSE, 1999, p. 84). Assim, "ao manipular a máquina, o homem aprende que a obediência às instruções é o único meio de se obter resultados desejados. Ser bem-sucedido é o mesmo que adaptar-se ao aparato. Não há lugar para a autonomia" (MARCUSE, 1999, p. 80).

A crença no progresso da técnica também foi densamente discutida por Horkheimer e Adorno na obra "Dialética do esclarecimento: fragmentos filosóficos" (1985). O esclarecimento que tinha como função retirar os homens do obscurantismo e, portanto, do pensamento mítico e direcioná-los à autonomia e ao pensamento emancipado converteu-se, segundo os frankfurtianos, justamente em seu contrário. Ou seja, o desenvolvimento técnico-científico engendrou, majoritariamente, uma espécie de regressão na totalidade do indivíduo, tanto em sua capacidade de pensar quanto de sentir. Nesses termos, Adorno (1995) afirma que a técnica deveria ser o braço estendido do homem a fim de facilitar a execução de suas atividades cotidianas, tornando o seu trabalho menos cansativo e desgastante. Nas palavras do pensador:

\footnotetext{
...os homens inclinam-se a considerar a técnica como sendo algo em si mesma, um fim em si mesmo, uma força própria, esquecendo que ela é a extensão do braço dos homens. Os meios - e a técnica é um conceito de meios dirigidos à autoconservação da espécie humana - são fetichizados, porque os fins - uma vida humana digna - encontram-se encobertos e desconectados da consciência das pessoas (ADORNO, 1995, p. 132-133).
}

Dessa maneira, o não reconhecimento da técnica como produto do trabalho humano oblitera as condições necessárias para a construção do conhecimento crítico e para a transformação da consciência reificada em consciência crítica. Assim, a técnica está cada vez mais distanciada da possibilidade de promover uma vida mais humana, já que passando a ser o braço prolongado do capitalismo e não mais dos indivíduos tem sido utilizada para a obtenção de "mais-valia relativa" em tempos de revolução microeletrônica. Nesse sentido, o aprimoramento da técnica presente nas tecnologias educacionais tem como finalidade a produção do trabalho especializado para a obtenção de mais capital, de acumulação de bens materiais e da dissolução praticamente absoluta entre as esferas do trabalho e do chamado tempo livre. Desse modo, essas tecnologias educacionais, ao contribuírem para a produção de profissionais especializados, afinados com a técnica, distanciam esses mesmos profissionais do exercício de atenção que é necessário para se relacionarem com os conteúdos disciplinares durante o período de sua formação. Tal distanciamento se confirma na maneira acrítica de utilização das plataformas digitais, que em vez de servirem como ferramentas 
para aproximar os estudantes da formação cultural, têm fomentado a chamada distração concentrada e fortalecido a semiformação.

\section{A distração Concentrada nas malhas do ensino Personalizado}

Para desenvolver a reflexão sobre a forma que professores e alunos têm apresentado dificuldades de se relacionar efetivamente com os materiais de estudos, é bastante pertinente a discussão feita por Christoph Türcke (2010a) acerca da contribuição dos aparatos tecnológicos que têm intensificado a desatenção nos estudos, à medida que promovem a chamada distração concentrada. O pensador esclarece que os choques audiovisuais disseminados por esses aparatos tecnológicos afetam a capacidade de concentração quando “[...] de modo fulminante, o choque concentra a atenção num ponto, para poder triturar essa concentração através de incontáveis repetições. O meio de concentração é, propriamente, o meio de decomposição" (TÜRCKE, 2010a, p. 266). Dessa maneira, as plataformas digitais são usadas como tentativa de captar a atenção dos alunos, contudo, a capacidade de se deterem é solapada em função da quantidade de atividades on-line que podem realizar simultaneamente sem, no entanto, se envolverem efetivamente com nenhuma. Os alunos que utilizam a plataforma Geekie podem acessar em "Plano de estudos" trinta e sete "Fases" contendo em cada "Fase" dois a quinze assuntos diferentes que disponibilizam videoaulas, questões, testes etc., além de opções interativas presentes em "Simulados", "Outras aulas" e "Desempenho". Acessando "Configurações", os alunos ainda têm acesso a quatro "Ritmos de estudo" que vão de "rápido" (30 minutos/dia), "moderado" (1 hora/dia), "sério" (2 horas/dia) e "intenso" (3 horas/dia). Podem também orientar os estudos escolhendo em "Curso/Faculdade", a graduação e a universidade de seu interesse, pois de acordo com informações do site, "conforme o curso algumas matérias tem mais importância. Por isso, [escolha] seu curso para o estudo ficar mais focado". Ou seja, as múltiplas opções oferecidas por uma plataforma como a Geekie podem, em vez de dinamizar e facilitar a aprendizagem, fazer que os estudantes se dispersem em meio a tantos recursos digitais, já que "navegar" pelo site da plataforma pode se tornar bem mais interessante que direcionar a atenção para assistir as videoaulas e resolver as questões e os simulados.

Essa dificuldade de os alunos se concentrarem nos conteúdos disciplinares é uma manifestação da chamada cultura do déficit de atenção discutida por Türcke (2010b). O pensador assevera que a atenção que os estudantes não conseguem direcionar para os estudos é produto da privação de uma atenção que não foi dada a eles por suas famílias durante a primeira infância. De acordo com Türcke (2010b), a criança experimenta a privação da atenção quando, no convívio com os pais, precisa conviver também com os aparatos tecnológicos que são objetos da atenção de seus progenitores. Nas palavras do pensador: 
camente como a atenção das pessoas de sua relação mais próxima se distribui entre elas e o bastidor, como a dedicação interpessoal se torna rasa e irreal entre as reivindicações de atenção que esse bastidor exige permanentemente (TÜRCKE, 2010b, p. 310-311).

Segundo Türcke (2010b), quando essas crianças crescem, passam a procurar nos aparelhos tecnológicos, como o computador atrelado à internet, a atenção que lhes foi roubada. Assim, as crianças "[...] procuram silêncio e segurança exatamente nas máquinas, que elas vivenciaram de modo difuso, pré-objetal de certo modo fantasmático, mas as quais, mesmo assim, cunharam-nas enquanto instauradoras da sua inquietação impedindo a sua segurança interna" (TÜRCKE, 2010b, p. 311). Dessa forma, o déficit de atenção que é vivido pelos estudantes, ao utilizarem as plataformas digitais, pode ser entendido como uma tentativa de busca da atenção de que foram privados, por isso, a dificuldade de se aterem sobre as informações que entram em contato. Esses estudantes, como explica o pensador, "não conseguem concentrar-se em qualquer coisa, demorar-se em algo, construir uma amizade, perseverar num jogo comum; [...] começam tudo o que é possível e não terminam nada" (TÜRCKE, 2010b, p. 309).

Contraditoriamente, as plataformas digitais, ao disponibilizarem inúmeras informações acerca dos conteúdos escolares, permitindo a professores e alunos utilizá-las para o entendimento e a produção de conceitos, são as mesmas que estão distanciando tais indivíduos de uma formação emancipada, pois cada vez menos conseguem se demorar e refletir sobre tais informações no sentido de compreendê-las criticamente. Seguindo essa linha de raciocínio, Lash e Lury afirmam que, na sociedade da indústria cultural global ocorre uma espécie de canibalização da capacidade simbólica (LASH; LURY, 2007), de modo que a reflexão crítica sobre as informações coletadas pelo uso das redes sociais se arrefece cada vez mais.

Nesse contexto da sociedade da mídia ubíqua (FEATHERSTONE, 2009), o ensino personalizado oferece aos alunos inúmeras atividades virtuais, no entanto, em meio a muitas opções disponíveis para a aprendizagem dos conteúdos escolares a concentração não consegue se estabelecer. $\mathrm{Na}$ aula em que o aluno está assistindo há uma série de interações virtuais que podem ser realizadas por meio de jogos. Mal tendo acabado essa aula, a próxima vem com a mesma intensidade de atividades on-line que precisam ser feitas. Nessa ausência de tempo para que os conteúdos disciplinares possam ser aprendidos a concentração se dissipa, pois o ensino personalizado está ancorado na ideia de que quanto mais informação consumida tanto melhor será o aprendizado. Como assevera Türcke (2010a), entre uma informação e outra, entre um link e outro é exigido do sensório humano um grau de adaptação pontual e eficiente a fim de que possa ser feito o maior número de atividades simultaneamente. Estar aqui, ali e acolá passa a ser a medida capaz de avaliar o nível de aprendizagem dos alunos, pois quanto mais plataformas acessarem tanto mais informação poderá ser obtida. De acordo com Türcke (2010a, p. 267): 
produção e administração perpassa por ela, de tal modo que se apresenta como $o$ instrumento de ensino do futuro.

A tela, como bem apontou o pensador, entendida como capaz de amenizar os impasses educacionais tem promovido uma inquietação sensório-motora e, assim, contribuído para o esfacelamento do pensamento crítico e da capacidade de concentração. Como advertiram Horkheimer e Adorno (1985) o progresso se converte em regresso, pois o excesso de informações disponíveis, em vez de conduzir o indivíduo à formação cultural, tem encaminhado professores e alunos para o distanciamento da capacidade de pensar criticamente. Assim, os estímulos audiovisuais são de tal forma absolutizados que parecem independentes da história das relações humanas que os engendrara. Já em meados de 1960, Debord advertia que o "espetáculo não é um conjunto de imagens, mas uma relação social entre pessoas, mediada por imagens" (DEBORD, 1997, p. 14).

Face ao quadro contemporâneo, o ensino personalizado, por se adequar com frequência ao aluno evitando que suas dificuldades se tornem visíveis, não oferece possibilidades para que o estudante ao se deparar com suas próprias limitações de aprendizagem possa refletir sobre elas de modo que seja possível trabalhar no sentido de superá-las. Tal adequação acontece, por exemplo, na realização das avaliações escolares, como explica Rothman (2013), "quando feita online, a prova se adapta a cada aluno. Se ele acerta as respostas, o programa aumenta a dificuldade da próxima questão, até se certificar do quanto o aluno sabe sobre aquela matéria. Se erra, as questões ficam no mesmo nível ou até mais fáceis" (ROTHMAN, 2013, p. 68). Sendo assim, pode-se entender que o ensino personalizado contribui para promover uma dificuldade de o aluno lidar com resultados indesejáveis nos estudos que aparece, por exemplo, na obtenção de uma nota insatisfatória e/ou na dificuldade de aprender determinado conteúdo. Como efeito, tem-se a perda da capacidade de perceber as próprias dificuldades de aprendizagem, pois a todo o momento as atividades escolares se adaptam para que os erros sejam amenizados. Quando o aluno consegue realizar com êxito todas as tarefas solicitadas, porque estas passam a se adequar a ele, o exercício de lidar com a frustração e com o receio de não conseguir aprender se dissipa e, na mesma proporção, a capacidade crítica de refletir sobre o próprio processo formativo. Pois, na realidade, o aluno é pavlovianamente treinado a encontrar a resposta certa ao invés de ser estimulado a relacionar criticamente as informações entre si a ponto de engendrar novos conceitos. De certo modo, pode-se asseverar que essa proposta de ensino personalizado reatualiza a intenção de Skinner de capacitar o aluno a ditar seu próprio ritmo de estudo por meio da utilização das chamadas máquinas de ensinar presentes nas escolas estadunidenses na década de 1960 (SKINNER, 1972).

No contexto atual, os escritos de Türcke (2010a) a respeito da sociedade excitada demonstram que conseguir, simultaneamente, encontrar informações em diferentes locais sobre assuntos diversos tornou-se cada vez mais a exigência de um momento histórico que tem como característica a exploração do sensório humano e o enfraquecimento da experiência. "As ações da experiência estão em baixa", afirmou Benjamin (2012), porque um dos efeitos deletérios do desenvolvimento tecnológico é a expropriação da capacidade humana 
de realizar experiências. Por isso, o pensador entende o declínio da experiência como uma forma de pobreza, ou seja, como "uma forma completamente nova de miséria que recaiu sobre os homens com esse monstruoso desenvolvimento da técnica" (BENJAMIN, 2012, p. 124). Ancorado no pensamento benjaminiano, Bondía (2002) entende que "a experiência é o que nos passa, o que nos acontece, o que nos toca" (BONDÍA, 2002, p. 21). A experiência, segundo o pensador, vem sendo cada vez mais dificultada em função do excesso de informação e pela falta de tempo, fazendo que o indivíduo não consiga dar sentido a si próprio e ao que vivencia. Desse modo, a crítica benjaminiana de que os indivíduos estão "sendo privados de uma faculdade que parecia totalmente segura e inalienável: a faculdade de intercambiar experiências" (BENJAMIN, 2012, p. 213) permanece atual à medida que o ensino personalizado, pontual e fragmentado presente nas plataformas digitais dificulta a possibilidade de momentos formativos. Assim, o ensino personalizado reverbera a pobreza de experiências denunciada por Walter Benjamin, uma vez que professores e alunos encontram cada vez mais dificuldades de darem sentido aos seus trabalhos, de refletirem acerca do que já foi feito e narrarem aquilo que aprenderam. Ou seja, professores e alunos, ao se entregarem ingenuamente à promessa de resultados exitosos no processo educativo graças ao uso das plataformas digitais, inviabilizam a si mesmos a possibilidade de que algo realmente formativo possa lhes acontecer.

\section{CONSIDERAÇõES FINAIS}

As tecnologias educacionais, ao proporcionarem acesso às informações em diferentes fontes, ao facilitarem a pesquisa para a realização de trabalhos escolares e para a elaboração de textos acadêmicos como artigos científicos, dissertações e teses, tornam-se importantes fontes de estudos e pesquisas quando utilizadas de maneira crítica e autônoma. Desse modo, os recursos tecnológicos podem aproximar professores e alunos de uma formação emancipada quando, por exemplo, na sala de aula é apresentada por meio do projetor multimídia uma pintura de Picasso buscando, a partir de seus elementos estéticos, compreender conceitos filosóficos. Nesses termos, é importante ressaltar que este trabalho, ao fazer a crítica aos efeitos do uso acrítico das plataformas digitais no processo educativo, não está negando o caráter formativo das tecnologias educacionais quando utilizadas, problematizadas e discutidas criticamente. Adorno (1995), em diálogo com Becker e Kadelbach, ao pensar o caráter ambíguo da televisão assevera que se, por um lado, ela pode contribuir para aproximar os indivíduos da formação cultural ao transmitir conteúdos educativos. Por outro, a televisão está a serviço da deformação da consciência dos indivíduos ao disseminar ideologias dificultando um conhecimento crítico sobre a realidade. Sendo assim, como entende Adorno (1995), é preciso se relacionar com os aparatos tecnológicos sem tomá-los como expressão da verdade, idolatrando-os, ao mesmo tempo em que não é possível negar seu uso e seu caráter formativo.

A respeito da presença das tecnologias na educação, Paulo Freire (2000) também entende que elas não podem ser consideradas como solucionadoras dos problemas edu- 
cacionais, assim como não podem ser entendidas como um perigo que causará prejuízos ao processo educativo. Nesse sentido, o pensador não diviniza nem demoniza os aparatos tecnológicos, mas entende que é preciso utilizá-los e compreendê-los de maneira crítica, procurando desvelar as ideologias e as verdades neles embutidas. Sendo assim, não é negando ou idolatrando as tecnologias na educação que professores e alunos conseguirão se aproximar da formação cultural, mas realizando o exercício crítico de ao utilizá-las buscar compreender em sua forma e conteúdo, como adverte Freire (2000), "a favor de quê, de quem, contra o quê e contra quem" estão. Assim, de acordo com o pensador, já que não se pode ignorar a presença dos aparelhos tecnológicos como a televisão e o computador na educação, a escola precisa necessariamente realizar a reflexão crítica acerca da técnica e suas implicações para o processo educativo.

Realizar tal reflexão significa problematizar a relação entre professores e alunos e as consequências da utilização dos aparatos tecnológicos para a experiência formativa. Por um lado, professores e alunos podem fazer uso das tecnologias digitais visando alcançar a emancipação intelectual ao utilizá-las como ferramentas pedagógicas para compreender os conteúdos escolares e engendrar novos conceitos. Por outro lado, a utilização de tais tecnologias pode estar a serviço da perpetuação da semiformação, do espírito alienado e do distanciamento afetivo e dialógico entre professores e alunos. Assim, as tecnologias digitais devem ser empregadas de modo a revitalizar a experiência formativa com vistas a proporcionar momentos de confronto respeitoso de ideias, de criação e compreensão de conceitos e de afetividade no processo educativo. No entanto, como foi discutido neste artigo, é possível perceber o uso acrítico e a crença demasiada nas tecnologias educacionais como capazes de promover uma educação de qualidade ao oferecer um ensino mais "atraente" enredado à interatividade e à diversão como proposto pela plataforma Geekie. Nesse contexto, as tecnologias usadas na educação como no caso das plataformas digitais devem ser problematizadas, pois a utilização dessas ferramentas como forma de dinamizar o processo formativo tem promovido o distanciamento da formação cultural e o recrudescimento da distração concentrada. Ou seja, têm contribuído para que professores e alunos encontrem dificuldades de se deterem sobre aquilo que está lhes exigindo atenção à medida que é cada vez mais necessário acessar simultaneamente o maior número de informações disponíveis. Diante disso, em tempos de ensino mediado por tecnologias, o professor por meio do exercício de sua autoridade e de seu compromisso pedagógico para com seus alunos não "está fora de moda", como afirmou Skinner (1972), nem pode ser relegado a apêndice do processo do formativo. Pois a função do professor torna-se ainda mais importante ao ser responsável por mediar a discussão com os alunos sobre o caráter formativo e também alienador dos recursos tecnológicos. Nesse sentido, a utilização das tecnologias no espaço escolar deve estar arraigada à reflexão crítica de seu uso, de modo que seja possível promover uma formação voltada para a autonomia e para a construção do pensamento autodeterminado. 


\section{REFERÊNCIAS}

ADORNO, Theodor Wiesengrund. Educação e emancipação, 3. ed. Rio de Janeiro, RJ: Editora Paz e Terra, 1995, 190p.

ADORNO, Theodor Wiesengrund. Teoria da semiformação. In: PUCCI, Bruno; ZUIN, Antônio Álvaro Soares; LASTÓRIA, Luiz Antônio Calmon Nabuco (Org.). Teoria crítica e inconformismo: novas perspectivas de pesquisa. Campinas, SP: Autores Associados, 2010, 250p.

BENJAMIN, Walter. Experiência e Pobreza. In: BENJAMIN, Walter. Magia e técnica, arte e política: ensaios sobre literatura e história da cultura, 8. ed. rev. Trad. Sérgio Paulo Rouanet. São Paulo, SP: Brasiliense, 2012, 256p.

BENJAMIN, Walter. O narrador: considerações sobre a obra de Nicolai Leskov. In: BENJAMIN, Walter. Magia e técnica, arte e política: ensaios sobre literatura e história da cultura, 8. ed. rev. Trad. Sérgio Paulo Rouanet. São Paulo, SP: Brasiliense, 2012, 256p.

BONDIA, Jorge Larrosa. Notas sobre a experiência e o saber da experiência. Revista Brasileira de Educação: Rio de Janeiro, n. 19, abr. 2002, p. 20-28. Disponível em: http:// www.scielo.br/pdf/rbedu/n19/n19a02.pdf Acesso em: 8 abr. 2017.

DEBORD, Guy. A sociedade do espetáculo. Trad. Estela de Santos Abreu. Rio de Janeiro, RJ: Contraponto, 1997, 240p.

FEATHERSTONE, Mike. Ubiquitous media: an introduction. Theory, Culture \& Society: vol. 26 (2-3), 2009. Disponível em: $<$ http://tcs.sagepub.com/content/26/2-3.toc $>$ Acesso em: 5 maio 2017.

FRANCO, Renato Bueno. Tecnologia e cultura na época da globalização. In: ZUIN, Antônio Álvaro Soares; PUCCI, Bruno; RAMOS-DE-OLIVEIRA, Newton. (Orgs.). Ensaios frankfurtianos. São Paulo, SP: Cortez, 2004, 208p.

FREIRE, Paulo. Pedagogia da indignação: cartas pedagógicas e outros escritos. São Paulo, SP: Editora UNESP, 2000, 134p.

HORKHEIMER, Max; ADORNO, Theodor Wiesengrund. Dialética do esclarecimento: fragmentos filosóficos. Rio de Janeiro, RJ: Zahar, 1985, 224p.

LASH, Scott; LURY, Celia. Global culture industry. Cambridge: Polity, 2007, 248p.

LÉVY, Pierre. Cibercultura. Trad. Carlos Irineu da Costa. São Paulo: Editora 34, 1999, $264 p$. 
MARCUSE, Herbert. Algumas implicações sociais da tecnologia moderna. In: MARCUSE, Herbert. Tecnologia, guerra e fascismo. Trad. Maria Cristina Vidal Borba. São Paulo, SP: Editora Unesp, 1999, 369p.

MORAN, José Manuel. A contribuição das tecnologias para uma educação inovadora. Itajaí, SC: Contrapontos, vol. 4, n. 2, mai./ago. 2004, p. 347-356. Disponível em: $<$ http:// siaiap32.univali.br/seer/index.php/rc/article/view/785 > . Acesso em: 7 abr. 2017.

PUCCI, Bruno; RAMOS-DE-OLIVEIRA, Newton. O enfraquecimento da experiência na sala de aula. Campinas, SP: Pro-Posições, vol. 18, n. 1, jan./abr. 2007, p. 41-50. Disponível em: $<$ http://www.proposicoes.fe.unicamp.br/proposicoes/textos/52-dossie-puccib_etal. pdf $>$. Acesso em: 10 abr. 2017.

ROTHMAN, Paula. Educação sob medida. Revista Info. São Paulo: Editora Abril, ed. 328, p. 58-69, abr. 2013.

SKINNER, Burrhus Frederic. Tecnologia do ensino. São Paulo, SP: E.P.U Editora Pedagógica e Universitária, 1972, 260p.

TÜRCKE, Christoph. Filosofia do sonho. Trad. Paulo Rudi Scheider. Ijuí, RS: Editora Unijuí, 2010b, 328p.

TÜRCKE, Christoph. Sociedade excitada: filosofia da sensação. Trad. Antônio Álvaro Soares Zuin [et al.]. Campinas, SP: Editora da Unicamp, 2010a. 328p.

\section{DADOS DOS AUTORES:}

Camila Sandim de Castro

Doutoranda em Educação pelo Programa de Pós-Graduação em Educação da Universidade Federal de São Carlos (UFSCar). Professora da Rede Municipal de Ensino de Barroso/MG

- Brasil.camilasandim23@gmail.com

\section{Antônio Álvaro Soares Zuin}

Doutor em Educação pela Universidade Estadual de Campinas (UNICAMP). Professor titular do Departamento de Educação e do Programa de Pós-Graduação em Educação, Universidade Federal de São Carlos. Bolsista Produtividade em Pesquisa CNPq. São Carlos/ SP - Brasil.dazu@ufscar.br

Submetido em: 16/05/2017

Aceito em: 21/05/2018 